\title{
Representing Earth Science Concepts through Slowmation: Influences on Conceptual Change
}

\author{
Reece Mills, Louisa Tomas Engel and Brian Lewthwaite \\ James Cook University
}

etropic 14.1 (2015): 5-12. http://www.reefandleaf.com.au/etropic.html \& http://www.jcu.edu.au/etropic

\begin{abstract}
It is well known that students arrive in science classrooms with pre-instructional ideas about science phenomena, and that often students' ideas are not scientifically accurate representations of these phenomena. This research project will engage Year 9 Science students in the creation of a slowmation to represent an Earth Science concept that has been misrepresented in popular culture, in an effort to support their conceptual change towards an accepted scientific understanding. A slowmation representation is a form of stop-motion animation. During the process of creating a slowmation representation, students will manipulate and photograph a range of materials to represent an Earth Science concept, and display the photographs in quick succession to create an animation. Students will then add their own narration that explains the concept. This research aims to determine: (1) Does the process of creating a slowmation representation have a significant effect on students' conceptual development in Earth Science? (2) How does the process of creating a slowmation representation influence students' conceptual development? and (3) To what extent does students' interest generated by the project influence their conceptual development? The project responds to calls for more in-depth research into the value of student-generated animation in science education (Hoban, Loughran, \& Nielsen, 2011; Hoban \& Nielsen, 2012), and contributes to the few studies that investigate the relationship between interest and conceptual change (Sinatra \& Mason, 2013; Treagust \& Duit, 2008).
\end{abstract}

Keywords: Earth Science; slowmation; conceptual change; alternative conception; misconception.

\section{Introduction}

Research in science education has shown that students commonly come to Science classes with pre-instructional alternative and misconceptions (Driver, 1989; Osborne \& Freyberg, 1985; Symington \& Northfield, 1991; White \& Gunstone, 1989). These alternative conceptions are often incomplete or incorrect and need to be better aligned with accepted scientific concepts. While the first author worked as a Science teacher, he noticed that students appeared to hold many alternative conceptions about Earth Science. He found encounters with students' alternative conceptions frustrating because they often persisted after instruction, despite attempts at facilitating conceptual development. It was obvious that students rote learnt conceptual knowledge for tests and that their alternative conceptions remained firmly held and resilient to change.

Often, students' alternative conceptions originated from popular culture. Science fiction abounds with examples of incorrect representations of Earth Science. Examples commonly 
given by the first author's Year 9 Science students during an Earth Science unit arose from the movie Ice Age: Continental Drift. In the movie trailer alone, there are a number of misrepresentations of important Earth Science concepts, including: (1) the geological time scale; (2) the rate of continental movement; and (3) the composition and depth of Earth's layers. Similarly, one of the first author's Year 12 Earth Science students watched the film Dante's Peak alongside the natural hazards unit they were completing, and reported to the class about the numerous misrepresentations of Earth Science that he noticed. The misrepresentations ranged from those that are farfetched, such as a scientist driving across a lava flow, to those that are more realistic, such as: (1) a volcano erupting both basaltic and pyroclastic flows; (2) an earthquakes large enough to collapse buildings and roads accompanying a volcanic eruption; and (3) a lakes near a volcano becoming acidic enough to be dangerous in a matter of minutes.

Empirical research, too, suggests that misrepresentations of Earth Science in popular culture negatively influence students' ideas. One study demonstrated that students who watched a science fiction movie, The Core, performed significantly worse on an end of term test than students who did not watch the movie (Barnett et al., 2006). At interviews conducted after the test, students often described exact scenes from the movie to support their answers. The authors found that students believed the science represented in the movie because of students' perceived authority of main character, and the movie images being more memorable than hands-on experiences (Barnett et al., 2006).

Given the tenacious nature of students' alternative conceptions, it appears that science fiction, and popular culture more broadly, may present an obstacle to learning in Earth Science. Although there is a need for constructivist instructional approaches that take into consideration the ideas that students bring with them to science classrooms, due to the instructional demand of such approaches, there remains a call for "efficient conceptual change instruction strategies” (Treagust \& Duit, 2008, p. 35). Research has shown that science teachers continue to favour transmissive models of learning and are ill-informed about and illequipped to enact conceptual change approaches to learning in Science (Duit, Widodo, \& Wodzinski, 2007). Recently, student-generated animation has been suggested as an efficient approach for bringing about conceptual change in science.

\section{Slowmation as a Conceptual Change Approach to Learning in Earth Science}

Overall, there is very little research on conceptual change in Earth Science education. This is not surprising, given that the Physics and Chemistry disciplines have dominated research in this field since the 1980s. Like Physics and Chemistry, however, Earth Science has concepts and processes that cannot be directly observed, and the geologic timescale inherit to the field is difficult for students to grasp. The researcher conducted a systematic literature review that revealed one study on secondary school students' pre-instructional conceptions about plate tectonics and continental movement (Marques \& Thompson, 1997). No studies were found on secondary school students' pre-instructional conceptions about geologic activity, including volcanoes and earthquakes. Few studies explored conceptual change approaches in an Earth Science context. Some approaches that have been successful in bringing about conceptual change in a secondary Earth Science context included inquiry- and problem-based learning, and the use of a simulation (Chang \& Barufaldi, 1999; Trundle, Atwood, Christopher, \& Sackes, 2009; Tsai \& Chang, 2005). 
There is also a paucity of research on the learning potential of student-generated animations. A number of studies have noted the educational value of students creating animations in Chemistry (Chang, Quintana, \& Krajcik, 2010; Schank \& Kozma, 2002; Stieff \& Wilensky, 2003; Wilder \& Brinkerhoff, 2007; Wu, Krajcik, \& Soloway, 2001), while another has examined the educational value of creating animations in Mathematics (Hubscher-Younger \& Narayanan, 2007). In both studies, the use of specially designed software packages increased students' conceptual understanding. For example, Year 7 students that used Chemation software to generate and explain an animation of a chemical reaction had significantly higher post-test scores than students who viewed and explained a teacher-generated animation (Chang at al., 2010). Other specially designed software (ChemSense, Connected Chemistry, Chemscape Chime and eChem) also yielded positive learning outcomes when students created their own animation (Schank \& Kozma, 2002; Stieff \& Wilensky, 2003; Wilder \& Brinkerhoff, 2007; Wu et al., 2001).

Student-generated animations that do not require specially designed software, such as slowmation, have been researched more recently. slowmation is a process where an animation is created from a series of still digital photographs that are displayed in quick succession (Hoban, 2005, 2007). The creation process involves two stages: (1) planning; and (2) creating (adapted from Hoban et al., 2011). In the slowmation creation process, students research a topic and then plan a storyboard. They use their own mobile phone, a digital camera, or an iPad to photograph a multi-modal two-dimensional or three-dimensional model as they manipulate it to demonstrate a concept or process (generally the model is flat on a table or on the floor). The photographs are then displayed at about two frames per second using software such as MovieMaker, or an application such as MyCreate.

There is a distinct call for further research about the process of creating a slowmation representation in science education. The key finding from a literature review carried out on this topic by the first author is that "there is scant published research pertaining to the use of slowmation in science education" and that "very few, if any, investigate the value of the teaching approach for student learning” (Hoban \& Ferry, 2006, p. 6). To date, the learning potential of creating a slowmation representation has not been researched in a junior secondary school context.

\section{Research Design and Procedures}

The following research questions have been formulated in response to the information above:

1. Does the process of creating a slowmation representation have a significant effect on students' conceptual development?

2. How does the process of creating a slowmation representation influence students' conceptual development?

3. To what extent does students' interest generated by the project influence their conceptual development?

In order to answer these questions, the researcher will conduct a classroom-based research project. The project will adopt a quasi-experimental design. Data will be generated from four Year 9 science classes at a Preparatory to Year 12 College in South-East Queensland, Australia. While two treatment classes will create slowmation representations of an Earth Science concept that has been misrepresented in popular culture, two comparison classes will follow the school's usual program of instruction. Pre- and post-test data will be collected from 
all classes. The treatment classes will be treated as a case study, and additional qualitative data will be collected. This will allow an in-depth insight into how the process of creating a slowmation influences students' conceptual development and the role interest plays in bringing about conceptual change.

\section{Organisation of the research project}

\section{Stage one: Development of the test instrument}

Data collection in this stage will occur in Term 4, 2014 (06/10/14 - 12/12/14)

The project will begin with the design of a three-tiered multiple-choice test instrument (Treagust, 1988) that will be used to identify students' alternative conceptions about several Earth Science concepts pre- and post-intervention. The instrument will test concepts specific to the Earth and Space Sciences substrand of the Foundation to Year 10 Australian Curriculum: Science (ACARA, 2014) and identified in the C2C unit Changing Earth (DETE, 2014a), as this is the unit of work common to Queensland students enrolled in state schools that will be undertaken during the implementation of the treatment.

The first tier of each item on the test will be a multiple-choice content question. The second tier will be a set of possible reasons for the answer given. The reasons will consist of the correct answer and any identified alternative conception/s, together with a wrong answer. Finally, the third tier will identify how confident a student is with their answer on a Likerttype scale (e.g., guessing, uncertain, confident, very confident), allowing the researcher to gain insight into how firmly students perceive that their conceptions are held. The design of the test instrument involves three tasks (Treagust, 1988): (1) define the Earth Science content; (2) research students' alternative conceptions; and (3) develop and validate the test instrument.

\section{Stage two: Pilot study}

Data collection in this stage will occur in Term 1, 2015 (27/01/15 - 02/04/15)

Stage two of the project involves teaching the teachers and students involved in the project how to create a slowmation and familiarising them with think-aloud protocols and the data collection equipment (i.e., audio-recording equipment). Data generated during this stage of the project will be treated as exploratory and used to refine the procedures used during the implementation of the intervention the following term in stage three.

\section{Stage three: Implementation of the research project}

Data collection in this stage will occur in Term 2, 2015 (20/04/15 - 26/06/2015)

The intervention will be implemented in stage three of the project. While the two treatment classes will create a slowmation representation of an Earth Science concept, the two comparison classes will experience 'teaching as usual' in alignment with the school's usual program of instruction. Each will span two 70-minute lessons (i.e., 140 minutes).

In developing the treatment, the researcher will identify the most common alternative conception held by students using the results of the test administration during stage one (development of the test instrument). Students will re-represent the most commonly held alternative conception through their slowmation (i.e., all students will create a slowmation representing the same concept). At the beginning of the first lesson for the two treatment classes there will be a short episode of direct teaching lasting approximately 30 minutes. It is during this time that the students will view the popular culture reference that has misrepresented the Earth Science concept. Following this, students will begin the process of 
independently re-representing the concept by creating a slowmation. This will involve two tasks: (1) planning, and (2) creating (adapted from Hoban et al., 2011). The teacher will view students' storyboards and still photographs during this time, prompting them to explain their approach to completing the tasks.

'Teaching as usual' for the two comparison classes will be the College's enactment of the Australian Curriculum, namely the learning activities provided in the $\mathrm{C} 2 \mathrm{C}$ unit plan Changing Earth (DETE, 2014a). While the treatment classes are creating slowmation representations of an identified concept, the comparison classes will be participating in the corresponding $\mathrm{C} 2 \mathrm{C}$ lessons that present the same concept. This means that over the three science lessons, all four classes involved in the project will learn about one Earth Science concept. Example learning activities from the Changing Earth unit plan include viewing a PowerPoint presentation, drawing and labeling diagrams, watching short videos on YouTube, and engaging with interactive internet-based learning objects (DETE, 2014a). The learning activities will be adapted, as necessary, to span two lessons.

The project will be implemented in a manner that ensures any significant conceptual development arising from the treatment classes can be confidently attributed to the treatment. To achieve this, both pairs of treatment and comparison classes will be taught by the same teacher. Also, all classes will experience the same short episode of direct teaching before the treatment classes create their slowmation representations and the comparison classes complete the C2C learning activities. Other variables will be made comparable by the researcher's choice of statistical tests during data analysis.

\section{Methods of data generation and analysis}

\section{Methods of data generation}

Data pertaining to students' conceptual development will be generated from:

- A pre- and post-test;

- Students' sketches and slowmation representations of an Earth Science concept;

- Audio recordings of students thinking-aloud during the creation of their slowmation representations; and

- Semi-structured, in-depth interviews.

Data pertaining to students' interest generated by the project will be gathered using a pre- and post-treatment questionnaire that has been adapted from the 2006 Programme for International Student Assessment student questionnaire (Organisation for Economic Cooperation and Development (OECD), 2014) and by qualitative analysis of the audio recordings and interview transcripts.

\section{Methods of data analysis}

Paired-samples $t$-tests will be used to determine if there are significant differences between the comparison and treatment classes, and if there is significant improvement in mean pre-test scores for students in the treatment classes. A correlation analysis will determine if there is a relationship between students' conceptual development and their interest generated by the project, and the strength of any relationship. Audio recordings of students thinking aloud during the creation of their slowmation and at interview will be fully transcribed and analysed in a typical qualitative manner (Creswell, 2007). An initial exploratory analysis will be carried out by reading all transcripts in their entirety several times to gain a general sense of the data. Following this, the transcripts will be divided into segments of text and coded in a 
manner representative of their meaning. Three preliminary codes will be used to organise spoken data in accordance with the research questions. As analysis progresses, further codes will be identified for each research question. The codes will be reviewed several times until key themes emerge.

\section{Expected Outcomes and Conclusion}

It is important that conceptual change research in Earth Science education is developed since Australia's national curriculum now mandates that students in Year 9 Science are required to learn about Earth Science concepts such as plate tectonics, continental movement, and geologic activity including earthquakes and volcanoes. In Queensland, where this study is located, this is embedded within a mandated Science unit for state schools in the Curriculum into the Classroom (C2C) unit Changing Earth (Department of Education, Training and Employment (DETE), 2014a). This is not an isolated occurrence of Earth Science across the national curriculum. Queensland students in Year 8 Geography also complete a C2C unit titled Landscapes (DETE, 2014b) and in Year 10 Science a C2C unit titled The Universe (DETE, 2014c).

This research project seeks to make a significant contribution to the limited conceptual change research in Earth Science education. The project responds to the paucity of studies that explore students' alterative conceptions about Earth Science, and the call for "efficient conceptual change instruction strategies” (Treagust \& Duit, 2008, p. 35). The research aims, therefore, have practical implications for both general and Earth Science teachers and teacher educators, which is crucial if the theory-practice gap in relation to conceptual change research is to be narrowed (Duit, Treagust, \& Widodo, 2013; Treagust \& Duit, 2008).

This research project will also seek to explore the learning potential of student-generated animation as a potential conceptual change pedagogy, specifically in a junior secondary Earth Science context. While student-generated animation has been suggested as an effective conceptual change approach to learning in pre-service teacher education, no studies to date have investigated this in a secondary school context. If creating a slowmation representation is found to contribute to students' conceptual development, the project's findings can inform teachers' choice of instructional approach so that they are able to align better students' preinstructional conceptions with accepted scientific views.

\section{Works Cited}

Barnett, M., Wagner, H., Gatling, A., Anderson, J., Houle, M., \& Kafka, A. (2006). The Impact of Science Fiction Film on Student Understanding of Science. Journal of Science Education and Technology, 15(2), 179-191.

Chang, C.-Y., \& Barufaldi, J. P. (1999). The use of a problem-solving-based instructional model in initiating change in students' achievement and alternative frameworks. International Journal of Science Education, 21(4), 373-388. doi:10.1080/095006999290606

Chang, H.-Y., Quintana, C., \& Krajcik, J. S. (2010). The impact of designing and evaluating molecular animations on how well middle school students understand the particulate nature of matter. Science Education, 94(1), 73-94. doi:10.1002/sce.20352 
Creswell, J. W. (2007). Qualitative inquiry and research design: Choosing among five approaches (2nd ed.). Thousand Oaks, CA: Sage.

Department of Education Training and Employment (DETE). (2014a). Changing earth. Retrieved August 23, 2014, from https://www.scootle.edu.au/ec/p/home

DETE. (2014b). Landscapes. Retrieved August 23, 2014, from https://www.scootle.edu.au/ec/p/home

DETE. (2014c). The universe. Retrieved August 23, 2014, from https://www.scootle.edu.au/ec/p/home

Driver, R. (1989). Students' conceptions and the learning of science. International Journal of Science Education, 11(5), 481-490. doi:10.1080/0950069890110501

Duit, R., Treagust, D. F., \& Widodo, A. (2013). Teaching science for conceptual change: Theory and practice. In S. Vosniadou (Ed.), International handbook of research on conceptual change (2nd ed., pp. 487-503). New York, NY: Routledge.

Duit, R., Widodo, A., \& Wodzinski, C. T. (2007). Conceptual change ideas - teachers' views and their instructional practice. In S. Vosnaidou, A. Baltas, \& X. Vamvokoussi (Eds.), Re-framing the problem of conceptual change learning and instruction (pp. 197-217). Amsterdam: Elsevier.

Hoban, G. (2005). From claymation to slowmation: A teaching procedure to develop students' science understandings. Teaching Science, 51(2), 26-30.

Hoban, G. (2007). Using slowmation to engage preservice elementary teachers in understanding science content knowledge. Contemporary Issues in Technology and Teacher Education, 7(2), 75-91.

Hoban, G., Loughran, J., \& Nielsen, W. (2011). Slowmation: Preservice elementary teachers representing science knowledge through creating multimodal digital animations. Journal of Research in Science Teaching, 48(9), 985-1009. doi:10.1002/tea.20436

Hoban, G., \& Nielsen, W. (2012). Using “slowmation” to enable preservice primary teachers to create multimodal representations of science concepts. Research in Science Education, 42(6), 1101-1119. doi:10.1007/s11165-011-9236-3

Hubscher-Younger, T., \& Narayanan, N. H. (2007). Turning the tables: Investigating characteristics and efficacy of student-authored multimedia representations. In R. Lowe \& W. Schnotz (Eds.), Learning with animations (pp. 235-262). New York, NY: Cambridge University Press.

Organisation for Economic Co-operation and Development (OECD). (2014). Database PISA 2006. Retrieved September 09, 2014, from http://pisa2006.acer.edu.au

Osborne, R., \& Freyberg, P. (1985). Learning in science: The implications of children's science. Portsmouth, NH: Heinmann Educational Books.

Schank, P., \& Kozma, R. (2002). Learning chemistry through the use of a representationbased knowledge building environment. Journal of Computers in Mathematics and Science Teaching, 21(3), 253-279.

Sinatra, G. M., \& Mason, L. (2013). Beyond knowledge: Learner characteristics influencing conceptual change. In S. Vosniadou (Ed.), International handbook of research on conceptual change (2nd ed., pp. 377-394). New York, NY: Routledge.

Stieff, M., \& Wilensky, U. (2003). Connected chemistry - incorporating interactive simulations into the chemistry classroom. Journal of Science Education and Technology, 12(3), 285-302. doi:10.1023/A:1025085023936

Symington, D. J., \& Northfield, J. R. (1991). Learning in science viewed as personal construction: An Australasian perspective. National Key Centre for Science and Mathematics, Curtin University, Perth. 
Treagust, D. F. (1988). Development and use of diagnostic tests to evaluate students' misconceptions in science. International Journal of Science Education, 10(2), 159-169. doi:10.1080/0950069880100204

Treagust, D. F., \& Duit, R. (2008). Conceptual change: A discussion of theoretical, methodological and practical challenges for science education. Cultural Studies of Science Education, 3(2), 297-328. doi:10.1007/s11422-008-9090-4

Trundle, K. C., Atwood, R. K., Christopher, J. E., \& Sackes, M. (2009). The effect of guided inquiry-based instruction on middle school students' understanding of lunar concepts. Research in Science Education, 40(3), 451-478. doi:10.1007/s11165-009-9129-x

Tsai, C.-C., \& Chang, C.-Y. (2005). Lasting effects of instruction guided by the conflict map: Experimental study of learning about the causes of the seasons. Journal of Research in Science Teaching, 42(10), 1089-1111. doi:10.1002/tea.20089

White, R. T., \& Gunstone, R. F. (1989). Metalearning and conceptual change. International Journal of Science Education, 11(5), 577-586. doi:10.1080/0950069890110509

Wilder, A., \& Brinkerhoff, J. (2007). Supporting representational competence in high school biology with computer-based biomolecular visualisations. Journal of Computers in Mathematics and Science Teaching, 26(1), 5-26.

Wu, H.-K., Krajcik, J. S., \& Soloway, E. (2001). Promoting understanding of chemical representations: Students' use of a visualization tool in the classroom. Journal of Research in Science Teaching, 38(7), 821-842. doi:10.1002/tea.1033

Ying-Shao, H. (2008). Learning about seasons in a technologically enhanced environment: The impact of teacher-guided and student-centered instructional approaches on the process of students' conceptual change. Science Education, 92(2), 320-344.

doi:10.1002/sce.20242 